Article

\title{
Investigation of Pedestrian Comfort with Wind Chill during Winter
}

\author{
Hyungkeun Kim ${ }^{\circledR}$, Kyungsoo Lee and Taeyeon Kim * \\ Department of Architectural Engineering, Yonsei University, Seoul 03722, Korea; hang0621@hanmail.net (H.K.); \\ draftday1209@yonsei.ac.kr (K.L.) \\ * Correspondence: tkim@yonsei.ac.kr; Tel.: +82-2-2123-5783
}

Received: 5 December 2017; Accepted: 18 January 2018; Published: 22 January 2018

\begin{abstract}
Two types of methods are used to evaluate pedestrian comfort: pedestrian wind comfort and outdoor thermal comfort. To accurately ascertain the outdoor wind environment, wind speed is the only parameter considered. However, pedestrians may still feel discomfort when the perceived temperature is low, even though the wind comfort criterion has been satisfactorily fulfilled. The purpose of this study is, therefore, to investigate pedestrian comfort when the perceived temperature is low, especially in winter conditions. To achieve this, a pedestrian survey was conducted, and 588 respondents completed a questionnaire. The results show that pedestrians feel discomfort when the WCET (Wind Chill Equivalent Temperature) is low, with almost 40 percent of respondents answering that they feel discomfort in these conditions. In conclusion, the threshold wind speed of the winter season could be determined to be lower than that of the existing comfort criteria by applying the WCET.
\end{abstract}

Keywords: pedestrian comfort; outdoor wind comfort; thermal comfort; wind chill; comfort criteria

\section{Introduction}

Recently, there has been an increase in the construction of high-rise buildings in cities; therefore, the microclimate around the buildings has changed. High speed winds that occur around high-rise buildings are introduced at the ground level and have a negative impact on the wind environment of pedestrians. Thus, pedestrian discomfort increases, and safety problems occur due to strong winds. In fact, there have been reports of cases in which an unpleasant outdoor wind environment leads to an untenanted building due to few visits from customers [1]. In addition, there have been reported incidents of death due to wind gusts that occur around high-rise buildings [2]. Therefore, the effects of mechanical forces of leaves and objects blown off by the wind should be considered to provide pedestrians with a pleasant and safe wind environment.

For the evaluation of the mechanical force effects, it is necessary to classify the effects of the mechanical force on the wind environment of pedestrians. Studies on the effects of winds on pedestrians have been performed by many researchers. Penwarden suggested that a wind speed of higher than $5 \mathrm{~m} / \mathrm{s}$ serve as a standard of the discomfort of pedestrians [3]. Lawson et al. added the effects of the wind speed on people to the "Land Beaufort Scale", which has widely been used in the field of meteorology [2]. Murakami et al. classified the degrees of the effects on pedestrians depending on the wind speed through wind tunnel experiments as well as field experiments and observations of the surroundings of high-rise buildings [4].

The frequency of occurrence at each location when the threshold wind speed is applied, as in the "Beaufort Scale", should be analyzed to evaluate the wind environment of pedestrians. Isyumov et al. classified the activities of pedestrians into walking fast, strolling, standing and sitting types, and then defined the frequency of occurrence to satisfy pedestrian comfort for each activity [5]. Accordingly, 
they could evaluate the number of times per year that exceeded the threshold wind speed. Among the annual frequency of occurrence at each location, the time that exceeds the threshold wind speed was defined as the probability of exceedance, and the pedestrian comfort criteria were devised through this probability. The Dutch wind nuisance standard NEN 8100 has recently been proposed. In the NEN 8100, the threshold values for the hourly mean wind speed were set to $5 \mathrm{~m} / \mathrm{s}$ and $15 \mathrm{~m} / \mathrm{s}$ for wind comfort and wind danger, respectively. In addition, the quality classes from A to E were presented in accordance with the range of the probability of exceedance [6].

Our research team performed an analysis on the pedestrian wind comfort of a high-rise building complex located in Beijing, China based on the criteria for pedestrian wind comfort according to the existing criteria. We then proposed a solution to reduce the wind speed by estimating the location where an unpleasant environment is expected to occur due to strong winds. However, complaints were reported after the completion of the project. In the process of analyzing the causes, we found that pedestrians feel discomfort even at a low wind speed due to thermal discomfort in addition to the wind speed. In other words, pedestrians perceive the low speed wind as a strong wind at low temperatures in winter and thus feel discomfort.

Lawson et al. mentioned that, because pedestrians adjust their clothing conditions to improve thermal comfort in outdoor environments where they stay for a relatively short time, the wind speed does not have a significant impact on the thermal comfort conditions [2]. Pedestrians tend to compensate for outdoor temperature changes by wearing appropriate clothing to maintain thermal comfort. However, this tendency is limited to cases in which the outdoor environmental conditions are not extreme. In particularly cold conditions, pedestrians can feel thermal discomfort through skin exposed to the cold, even though they wear thick clothes [7]. We reached the conclusion that additional measures are needed for the pedestrian wind comfort criteria if plans on the outdoor wind environment in winter are set up based on the existing studies and experience through a project.

The purpose of this study is to propose a method to improve the existing pedestrian wind comfort criteria. In the existing criteria, as stated before, wind speed was the only parameter used to evaluate pedestrian comfort. However, in certain conditions, especially in winter, pedestrians are likely to feel huge discomfort because of not only wind speed but also other parameters such as the air temperature. Toward this end, we combined thermal comfort elements to the reference parameter (threshold wind speed) of the existing pedestrian wind comfort. Since the 1980s, many studies have been conducted regarding pedestrian thermal comfort [8-10]. Since then, several studies on the external thermal comfort have continuously been performed with a focus on the summer season or warm sectors. On the other hand, there were fewer case studies focusing on cold areas or the winter season [11]. One of the methods commonly used to assess thermal comfort in winter is the wind chill, and the wind chill is applied in the field of pedestrian thermal comfort $[12,13]$.

A questionnaire survey was conducted based on guided interviews with pedestrians to evaluate the subjective perception of the wind environment of pedestrians. The survey was performed in a downtown area. The questionnaire included brief personal information, time, clothing value and a perception of the wind environment. From the results of the survey, the pedestrian perception of the outdoor wind environment was derived from the statistical method. The result of the pedestrian perception was compared with the WCET (Wind Chill Equivalent Temperature) and reference wind speed. An alternative plan was considered based on the results of the questionnaire survey.

\section{Evaluation Method of Pedestrian Comfort}

\subsection{Pedestrian Wind Comfort-Mechanical Effects}

Pedestrians feel discomfort when strong winds occur frequently. If pedestrians feel discomfort, they behave in a variety of ways to avoid these wind effects [14]. Thus, evaluation criteria are required to solve the pedestrian discomfort problems. In this regard, the pedestrian wind comfort criteria were 
devised. The method for evaluation of the pedestrian wind environment consists of the threshold wind speed and probability of exceedance.

The threshold wind speed for evaluating the pedestrian wind comfort refers to the standard of wind felt by pedestrians, and various values have been proposed through several studies $[15,16]$. The probability of exceedance represents the probability that exceeds the threshold wind speed. Based on these two factors, the criteria to assess the pedestrian wind comfort can be established.

There are several criteria for pedestrian wind comfort. The Lawson criterion is the most restrictive criteria. The threshold wind speed was divided into three categories based on pedestrian activities (Table 1). This criterion set a limit of 2 percent of exceedance probabilities for every activity. In recent years, a new standard for pedestrian wind comfort (NEN 8100) has been proposed in the Netherlands. In the NEN 8100, the threshold wind speed was set to $5 \mathrm{~m} / \mathrm{s}$, and the wind danger to $15 \mathrm{~m} / \mathrm{s}$ (Table 2). Many researchers also estimate that, as in the NEN 8100, pedestrian wind discomfort caused by winds does not occur if the wind speed does not exceed $5 \mathrm{~m} / \mathrm{s}$ [17].

Table 1. Wind comfort criteria of Lawson.

\begin{tabular}{ccc}
\hline Wind Speed Threshold & $\begin{array}{c}\text { Maximum Allowed } \\
\text { Exceedance Probabilities }\end{array}$ & Description of Activity \\
\hline $1.8 \mathrm{~m} / \mathrm{s}$ & $2 \%$ & long time outdoor sitting \\
$3.6 \mathrm{~m} / \mathrm{s}$ & $2 \%$ & standing or casual walking or sitting short time \\
$5.3 \mathrm{~m} / \mathrm{s}$ & $2 \%$ & strolling \\
\hline
\end{tabular}

Table 2. Wind comfort criteria of NEN 8100.

\begin{tabular}{ccccc}
\hline \multirow{2}{*}{$\begin{array}{c}\text { Probability of } \\
\text { Exceedance }\end{array}$} & Quality Level & $\begin{array}{c}\text { Activity-Level } \\
\text { I. Walking, } \\
\text { Normal Pace }\end{array}$ & $\begin{array}{c}\text { II. Walking, } \\
\text { Leisurely Strolling }\end{array}$ & $\begin{array}{c}\text { III. Sitting, } \\
\text { Longer Time }\end{array}$ \\
\hline $1-2.5$ & A & Good & Good & Good \\
$2.5-5$ & B & Good & Good & Moderate \\
$5-10$ & C & Good & Moderate & Poor \\
$10-20$ & D & Moderate & Poor & Poor \\
$\geq 20$ & E & Poor & Poor & Poor \\
\hline
\end{tabular}

Finally, the pedestrian wind comfort can be assessed through the exceedance probability on the threshold wind speed. The probability of exceedance is obtained by introducing a stochastic technique to calculate the probability of the threshold wind speed $(5 \mathrm{~m} / \mathrm{s}$; in general) at a particular position. Statistical data, a threshold wind speed and the Weibull parameter are all needed to calculate the exceedance probability in the existing comfort criteria. The probability of exceedance is calculated through the following equation:

$$
P_{\theta}\left(U_{\text {local }}>U_{t h r}\right)=100 \times A(\theta) \times \exp \left[-\left(\frac{U_{t h r}}{\gamma_{\theta} \cdot c(\theta)}\right)^{k(\theta)}\right]
$$

where $P_{\theta}$ is the probability of exceedance (\%), $U_{\text {local }}$ is the local wind speed, $U_{t h r}$ is the threshold wind speed $(\mathrm{m} / \mathrm{s}), A(\theta)$ is the probability for the wind direction $\theta$, and $c(\theta)$ and $k(\theta)$ are the Weibull parameters.

In the existing pedestrian wind comfort criteria, an identical threshold wind speed is applied during the whole year. However, pedestrian can feel wind discomfort at a smaller wind speed than the threshold wind speed in winter. For this reason, applying an identical threshold wind speed is not always appropriate in regions that have a long winter season. To solve this problem, wind chill was applied to the threshold wind speed in winter. 


\subsection{Wind Chill Index-Thermal Effect of Wind}

The effects of meteorological parameters on the thermal comfort vary depending on the season and time. In summer, an increase in temperature and humidity contributes to the higher perceived temperature. Conversely, the perceived temperature varies with the wind speed and temperature in winter. Greater wind speeds promote convective heat transfer, causing the body to lose heat quickly [18].

The wind chill index (WCI) was designed to evaluate the risk of freezing cold injuries such as frostbite. However, it has also been utilized as an indicator of thermal comfort evaluation in winter [19]. The thermal comfort of the human body is determined by various environmental factors such as air temperature, radiant temperature, humidity, wind speed, metabolic rate, clothing level and exposure time. However, the WCI can be calculated with two variables: air temperature and wind speed.

The WCI was first developed by weather services in the USA and Canada in the 1940s and has since gone through many improvements [20]. The $\mathrm{WCI}\left(\mathrm{W} / \mathrm{m}^{2}\right)$ is based on the cooling rate of a plastic bottle exposed on the outdoor environment. The WCET (or WCT) is based on a model of skin temperature under the outdoor environment with wind speed and temperature. The WCET is more suitable than WCI to evaluate the human perception of wind. The currently used WCET was developed by medical experts and scientists of the Joint Action Group for Temperature Indices (JAG/TI) in Canada and the United States in the winter of 2001. The WCET reflected the exposed skin temperature of the human body that changes in a variety of wind speed conditions. Twelve adults (six men and six women) were tested to evaluate wind chill. In addition, it assumed the average walking speed of a pedestrian to be $1.34 \mathrm{~m} / \mathrm{s}$. The wind chill equivalent temperature (WCET; $T_{W C}$ ) is calculated as follows [21].

$$
T_{W C}=13.12+0.6215 T_{a}-11.37 V^{0.16}+0.3965 T_{a} \cdot V^{0.16}
$$

where $T_{W C}$ is WCET $\left({ }^{\circ} \mathrm{C}\right), T_{a}$ is air temperature $\left({ }^{\circ} \mathrm{C}\right)$, and $V$ is air velocity $(\mathrm{km} / \mathrm{h})$.

Along with the pedestrian wind comfort criteria, the WCET has been utilized to evaluate pedestrian wind environment. To assess pedestrian comfort, Soligo et al. combined the existing mechanical effect of the wind with thermal effects. In this regard, this study proposed a new pedestrian comfort assessment program to ensure that the value of the WCET meets the minimum acceptable equivalent temperature of $-20^{\circ} \mathrm{C}$ and applied the probability indicating that the equivalent temperature of wind chill becomes less than $-20^{\circ} \mathrm{C}$ depending on the external wind speed to the pedestrian wind comfort. Szucs et al. utilized a new WCET to meet the thermal comfort of spectators in stadiums, which are semi-outdoor spaces. In this study, a parametric study was performed to find a condition in which WCET of the stadium becomes more than $0{ }^{\circ} \mathrm{C}$ based on the Wind comfort assessment method used by CSTB Nantes.

Mansoureh set the comfort range with respect to the indices that give thermal stress in the outdoor environment, and focused on the wind chill as a factor that gives cold stress. In particular, the author presented the thermal sensation felt by pedestrians depending on the range of WCET, as shown in Table 3 [22]. While the discomfort problem caused by wind chill is not great if the WCET ranges from 0 to $-10{ }^{\circ} \mathrm{C}$, the cold stress is felt if it is less than $-10^{\circ} \mathrm{C}$. Therefore, there is a need for a solution for cases in which the WCET is less than $-10{ }^{\circ} \mathrm{C}$. In this study, $-10{ }^{\circ} \mathrm{C}$ of WCET was used as the standard of the thermal sensation in outdoor environments with reference to the study of Monsoureh. By applying WCET, the threshold wind speed of the pedestrian wind comfort criteria can be modified. In this study, the questionnaire survey was performed to confirm this method. 
Table 3. Thermal sensation based on wind chill index.

\begin{tabular}{cc}
\hline WCET & Thermal Sensation \\
\hline-10 to 0 & Low cold stress \\
-25 to -10 & Moderate cold stress \\
-35 to -25 & Heavy cold stress \\
Less than -35 & Extreme cold stress \\
\hline
\end{tabular}

\subsection{Micrometeorological Measurement}

To investigate pedestrian wind comfort, the authors selected a district located in Seoul which experiences a particularly cold winter. A commercial district with high-rise buildings was chosen for this study. There is a subway station and three department stores in the area. This district has an average 28,299 people/day floating population [23]. Two locations through which many pedestrians pass were selected for measurement. The first location is in front of a subway exit that is the main route to the station square, and the second location is in front of the exit of a department store (Figure 1).

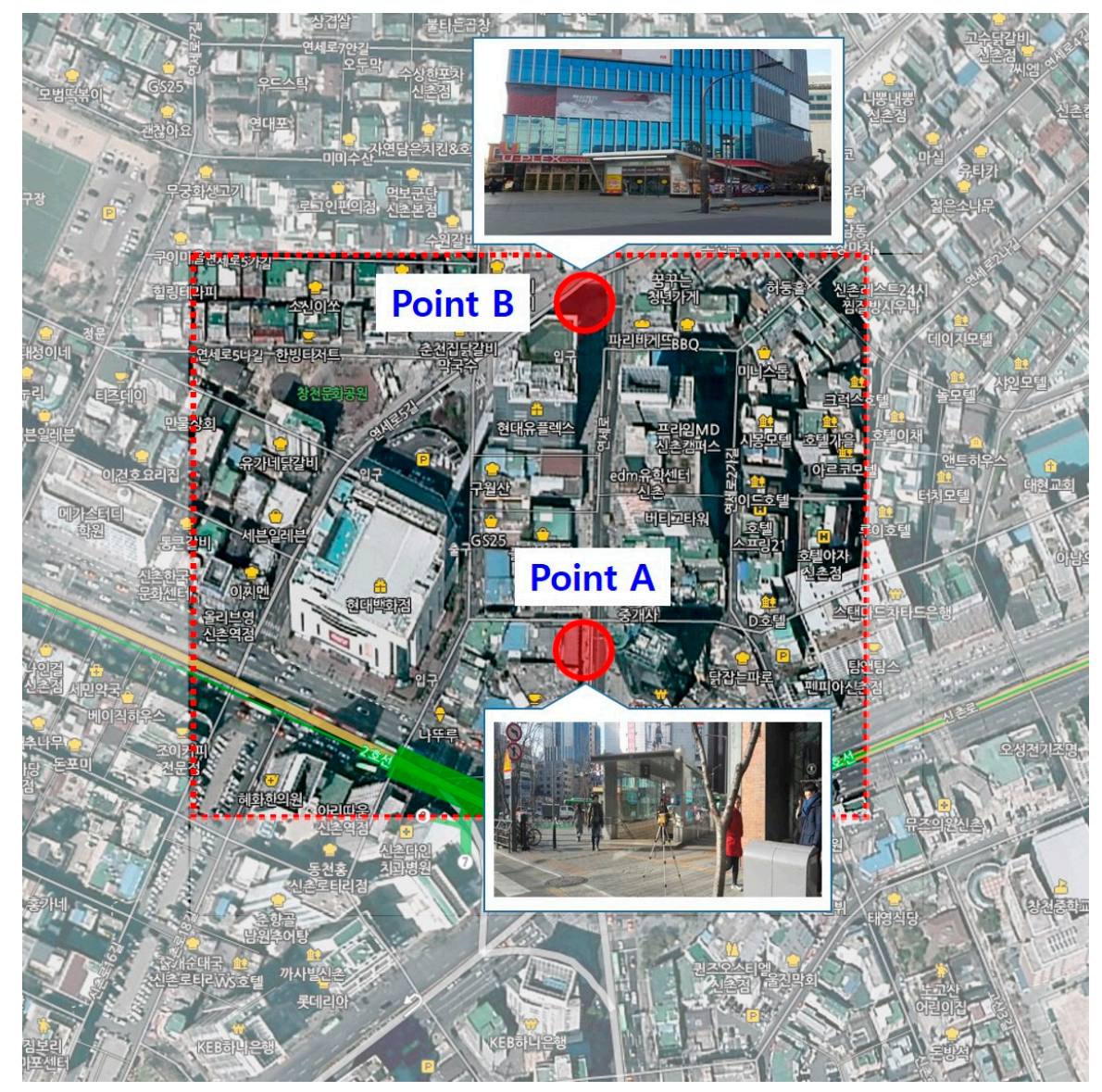

Figure 1. Measurement location for pedestrian comfort.

A field measurement was performed over 12 days when the average outdoor air temperature is predicted to be below $0{ }^{\circ} \mathrm{C}$ from January to February. Wind speed and outdoor air temperatures were measured for meteorological parameters. At each location, measuring equipment (TESTO-480) was set up. Wind speed, air temperature and relative humidity were recorded at $10 \mathrm{~s}$ intervals from 10:00 a.m. to 7:00 p.m. Finally, the measured data were calculated and the one-minute average ascertained. 


\subsection{Wind Perception Survey of Pedestrian}

The questionnaire survey was carried out by guided interviews with pedestrians around the project site. To investigate the subjective perception of the outdoor wind environment, researchers gave a brief explanation about the investigating items to respondents.

The investigating items contain survey time, gender, clothing level, strolling time (outdoors), subjective perception of wind and comprehensive comfort. The subjective perceptions of pedestrians were divided into two categories: pedestrian wind comfort (mechanical force of wind) and comprehensive pedestrian comfort (combined with temperature and relative humidity). These items were evaluated based on a four-point scale (0: Clearly unacceptable; 1 : Just unacceptable; 2 : Just acceptable; 3: Clearly acceptable). After the survey ended, measured data were matched with the survey results. In total, 588 respondents filled out a survey (female respondents: 208; male respondents: 380). Figure 2 shows the pedestrian perception of outdoor environment questionnaire.

\begin{tabular}{|c|c|c|c|c|c|}
\hline \multicolumn{6}{|c|}{$\begin{array}{l}\text { Pedestrian Survey } \\
\text { Subjective Perception of outdoor environment }\end{array}$} \\
\hline \multicolumn{2}{|r|}{ (1) Gender } & \multicolumn{2}{|c|}{ Male } & \multicolumn{2}{|c|}{ Female } \\
\hline \multicolumn{6}{|c|}{ (2) Response time } \\
\hline (4) & Wind acceptability & $\begin{array}{c}\text { clearly } \\
\text { unacceptable } \\
0\end{array}$ & $\begin{array}{c}\text { just } \\
\text { unacceptable } \\
1\end{array}$ & $\begin{array}{c}\text { just } \\
\text { acceptable } \\
2\end{array}$ & $\begin{array}{c}\text { clearly } \\
\text { acceptable } \\
3\end{array}$ \\
\hline (5) & $\begin{array}{l}\text { Comprehensive } \\
\text { comfort }\end{array}$ & $\begin{array}{c}\text { clearly } \\
\text { unacceptable } \\
0\end{array}$ & $\begin{array}{c}\text { just } \\
\text { unacceptable } \\
1\end{array}$ & $\begin{array}{c}\text { just } \\
\text { acceptable } \\
2\end{array}$ & $\begin{array}{c}\text { clearly } \\
\text { acceptable } \\
3\end{array}$ \\
\hline & $\begin{array}{l}\text { (6) outdoor } \\
\text { Residence Time }\end{array}$ & & & & \\
\hline
\end{tabular}

Figure 2. The questionnaire of pedestrian perception of outdoor environments.

\section{Data Analysis}

\subsection{Meteorological Data Statistics}

Outdoor wind speed and air temperature were measured while conducting pedestrian surveys in two different locations. Each datum was recorded at $10 \mathrm{~s}$ internals, and the average wind speed and air temperature were calculated over one minute.

The average wind speed of the site is shown in Figure 3. The maximum transient wind speed was $10.51 \mathrm{~m} / \mathrm{s}$, and the overall average wind speed was $3.21 \mathrm{~m} / \mathrm{s}$ with 1.85 standard deviation. The average wind speed is faster than the threshold wind speed according to the Lawson criterion. In the Lawson criterion, the frequency of exceedance to threshold wind speed is 37.78 percent (standing, casual walking or sitting short time) and 10.94 percent (strolling). In the NEN8100 criterion, the frequency of exceedance to threshold wind speed is 15.55 percent. In general, the wind speed of the site is faster than ordinary comfort wind conditions $(2.0-2.5 \mathrm{~m} / \mathrm{s}$ in winter).

The average outdoor air temperature of the site is shown in Figure 4. At almost every moment of the measurement period, the air temperature fell below $0{ }^{\circ} \mathrm{C}$. The range of the air temperature was a minimum $-6.1^{\circ} \mathrm{C}$ to a maximum $3.1{ }^{\circ} \mathrm{C}$. In comparison with the distribution of outdoor wind speeds, the outdoor air temperature was evenly distributed. The standard deviation of the air temperature was 2.29 . 


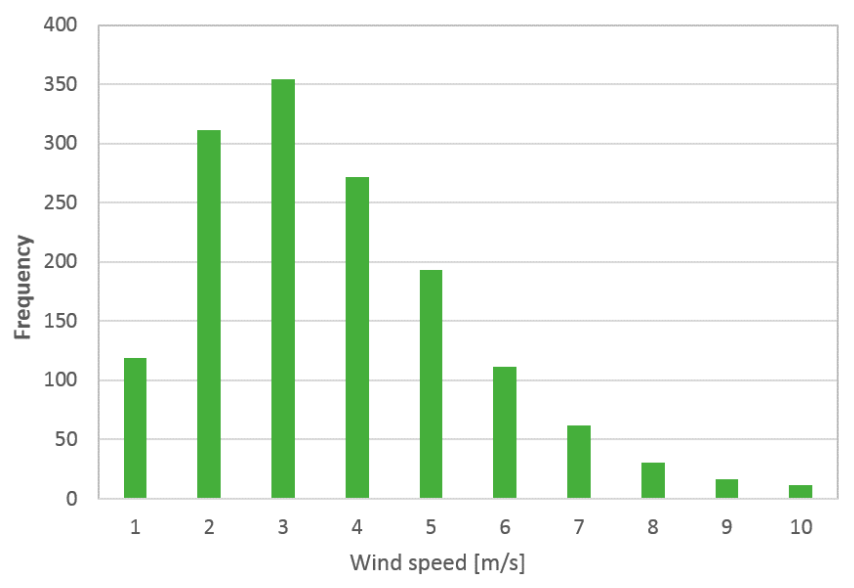

Figure 3. The measured wind speed of the site.

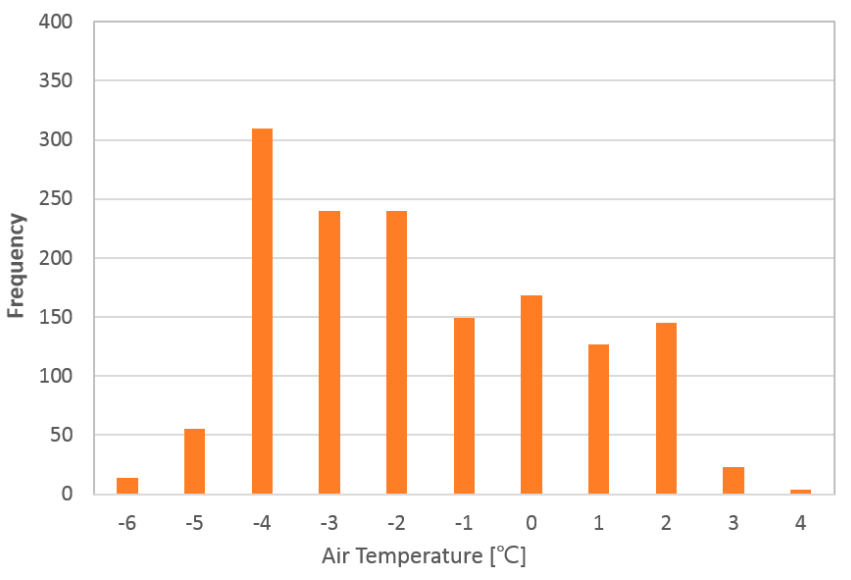

Figure 4. The measured air temperature of the site.

The WCET was calculated based on the measured wind speed and outdoor air temperature (Equation (1)). Figure 5 shows the calculated WCET $\left({ }^{\circ} \mathrm{C}\right)$. The WCET would represent the perceived temperature of pedestrian by combining wind speed with air temperature. The average WCET was $-5.79{ }^{\circ} \mathrm{C}$, which is much lower than air temperature. Because of strong winds, pedestrians could perceive lower temperatures than the actual air temperature. The trend of the WCET was evenly distributed and the standard deviation of WCET was $3.94{ }^{\circ} \mathrm{C}$. This means the perceived temperature could vary according to the wind speed.

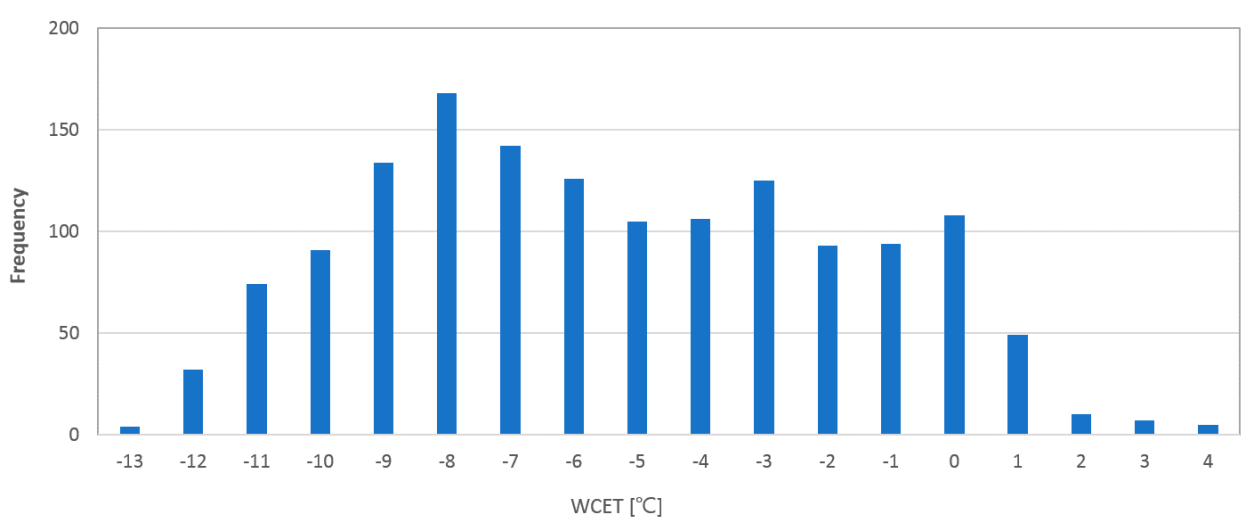

Figure 5. The calculated WCET of the site. 
In winter, perceived temperatures could be much lower than air temperatures because of strong winds. Perceived temperatures could by $5{ }^{\circ} \mathrm{C}$ lower than the air temperatures depending on the wind speed. Therefore, it is necessary to consider the WCET as a pedestrian comfort parameter in winter conditions.

\subsection{Survey of Pedestrian Comfort}

Figures 6 and 7 show the results of the rate of respondents of each comfort level. Figure 6 shows the result of pedestrian perceptions of wind environments which contains the wind speed as the only parameter. This represents the pedestrian perception based on the existing wind comfort criteria. Over 40 percent of respondents answered that they feel discomfort with the wind. Female respondents tend to feel discomfort more often than male respondents.

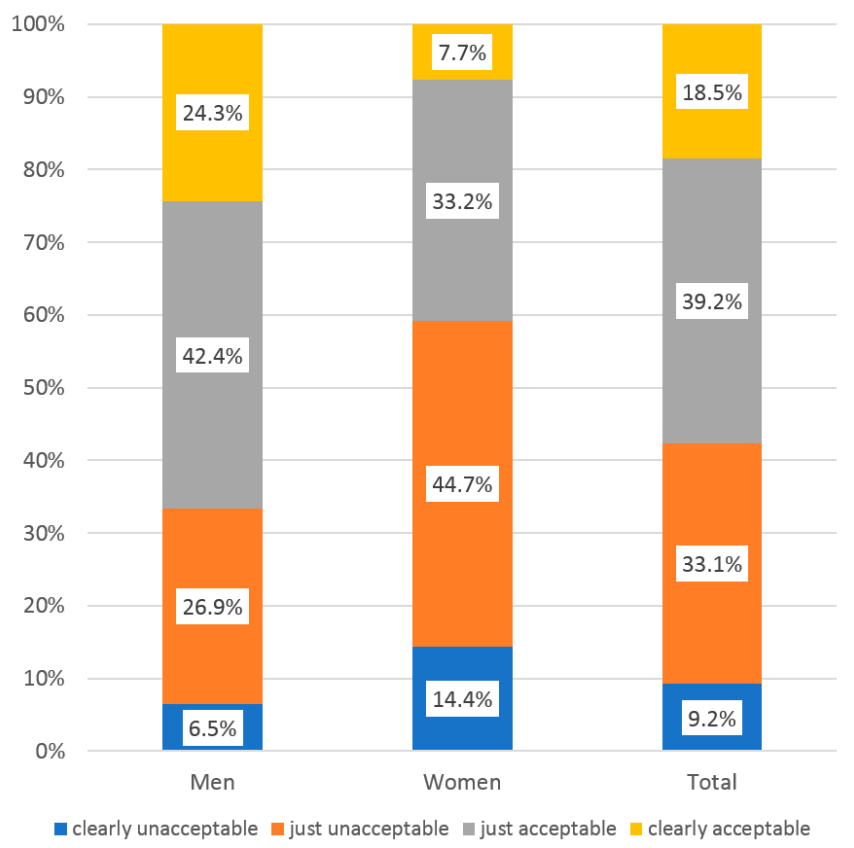

Figure 6. The result of pedestrian perceptions of wind environments.

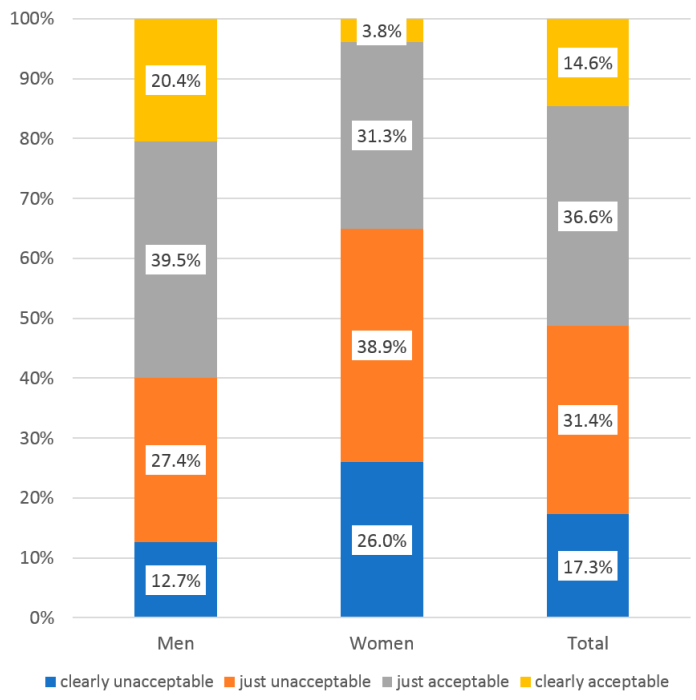

Figure 7. The results of the subjective perception of outdoor environments. 
Figure 7 shows the results of the subjective perception of outdoor environments which contain wind and air temperatures. This represents the comprehensive perception of the outdoor environment in winter. This is actual perception of pedestrians because they can feel discomfort by many parameters. Almost 50 percent of respondents answered that they feel discomfort at the square in winter. Particularly, the rate of clearly unacceptable feelings almost doubled in comparison with the rate of pedestrian perception of wind environments. Only 14.6 percent of respondents answered that they feel pleasant with regards the outdoor environment. Every respondent wore a heavy coat or parka, which are both very common garments in winter in South Korea (clothing value; clo 1.5-2.0; ISO 7730 standard). Although they were dressed warmly enough and with the appropriate clothes, almost every respondent confirmed that they felt discomfort. Pedestrians tend to feel more discomfort with lower air temperatures in winter conditions.

Figure 8 shows the result of the subjective wind perception vote of pedestrians. The $X$-axis shows air temperature and the $Y$-axis shows wind speed. The blue dotted line represents the threshold wind speed of the pedestrian wind comfort criterion of Lawson. The red curve and blue curve show the WCET line of $T_{W C}=-10$ and $T_{W C}=0$, respectively. The three grey dotted curves show the WCET lines of $T_{W C}=-5, T_{W C}=-3$ and $T_{W C}=-2$, respectively. These curves were illustrated in the graph to analyze the range of pedestrian discomfort.

Figure 8a shows the meteorological data of respondents who answered that they feel it is clearly unacceptable. In total, 115 respondents answered that the outdoor conditions are seen as clearly unacceptable. Ninety-eight percent of respondents answered that they feel discomfort when the wind speed is above $1.8 \mathrm{~m} / \mathrm{s}$ (the threshold of wind speed of sitting conditions). Ninety-one percent of respondents who feel discomfort answered that they feel discomfort when the air temperature is below $0{ }^{\circ} \mathrm{C}$. The average values of respondents who felt the situation to be "clearly unacceptable" were $-1.4{ }^{\circ} \mathrm{C}$ air temperature and $3.3 \mathrm{~m} / \mathrm{s}$ wind speed. This value is converted to WCET as $-5.47^{\circ} \mathrm{C}$. All data were under WCET $0{ }^{\circ} \mathrm{C}$. In total, 106 of 115 respondents answered that they feel discomfort when the WCET is below $-3^{\circ} \mathrm{C}$. According to this result, we can conclude that pedestrians may feel discomfort when the WCET is under $-3^{\circ} \mathrm{C}$.

Figure $8 \mathrm{~b}$ shows the meteorological data of respondents who felt the situation to be "unacceptable". In total, 195 respondents answered that the outdoor conditions were seen as "unacceptable". The average values of respondents who said the conditions to be unacceptable were $-0.9^{\circ} \mathrm{C}$ air temperature and $3.1 \mathrm{~m} / \mathrm{s}$ wind speed. This value is converted to WCET as $-4.69{ }^{\circ} \mathrm{C}$. Overally, 187 respondents belong to the zone where WCET is below $-2{ }^{\circ} \mathrm{C}$. Ninety-six percent of respondents who felt the situation to be merely unacceptable are included in this zone.

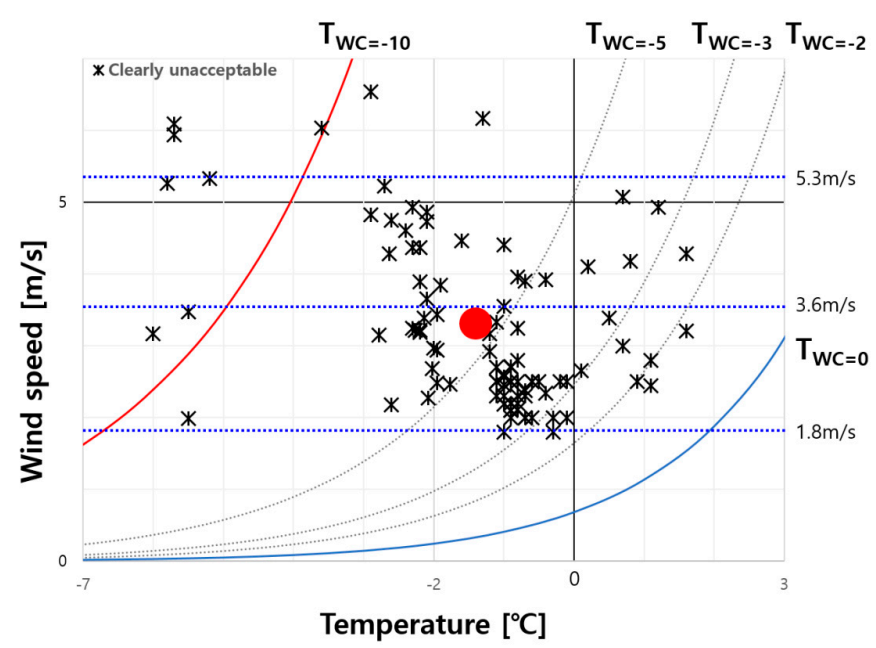

(a)

Figure 8. Cont. 


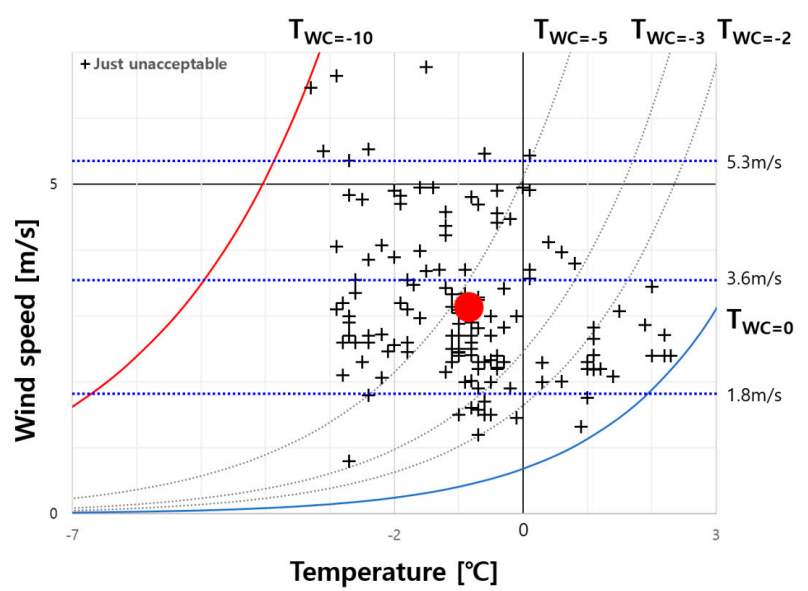

(b)

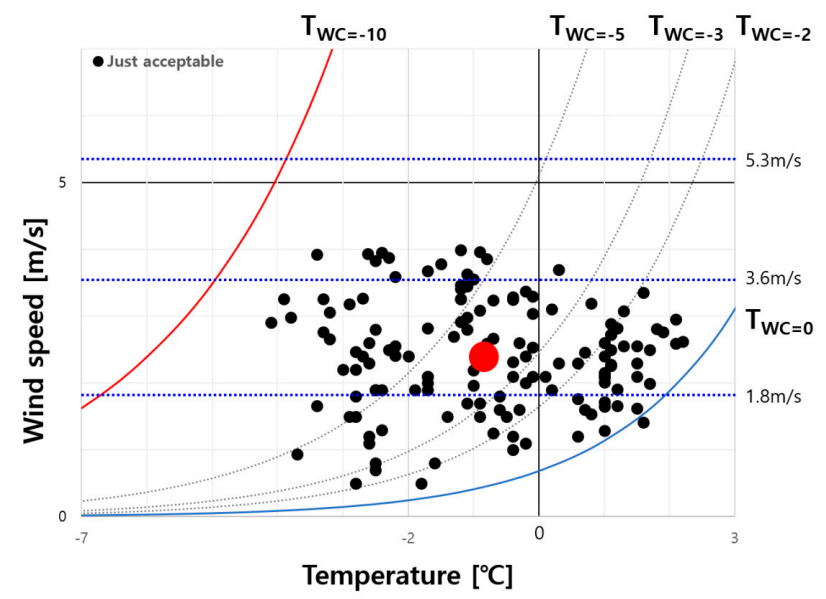

(c)

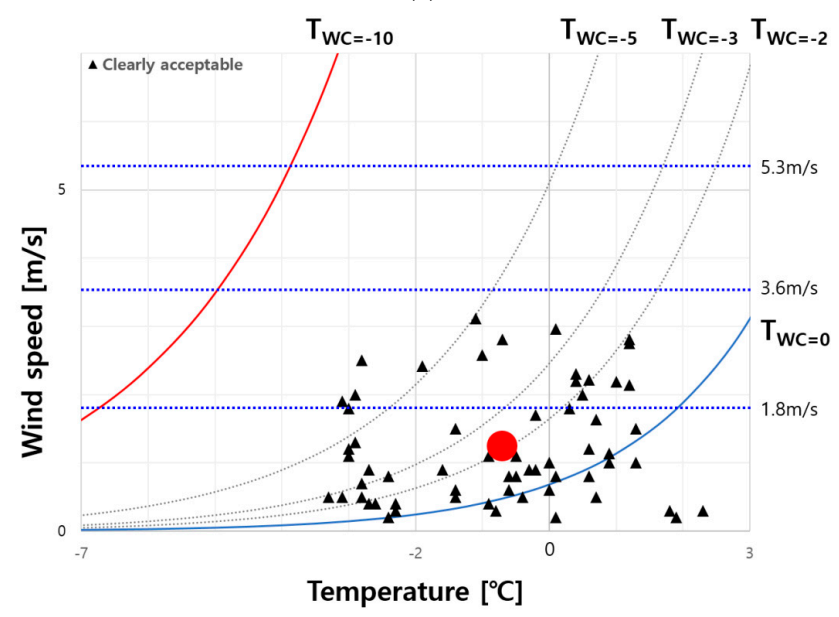

(d)

Figure 8. Pedestrians who felt the conditions were: (a) clearly unacceptable; (b) just unacceptable; (c) just acceptable; and (d) clearly acceptable.

In general, pedestrians felt discomfort when the WCET is around $-5^{\circ} \mathrm{C}$. The distribution charts in Figure $8 \mathrm{a}, \mathrm{b}$ are quite similar. There were no huge differences in terms of meteorological data between respondents who answered that the conditions were either clearly unacceptable or just unacceptable. Respondents tend to confuse these two answers. Almost all respondents who answered unacceptable 
indicated that they feel discomfort when the wind speed is over $1.8 \mathrm{~m} / \mathrm{s}$ and the air temperature is below $0{ }^{\circ} \mathrm{C}$.

Figure $8 \mathrm{c}$ shows the meteorological data of respondents who answered with "acceptable". The average value of respondents who answered just acceptable was $-0.8^{\circ} \mathrm{C}$ of air temperature and $2.4 \mathrm{~m} / \mathrm{s}$ of wind speed. This value is converted to WCET as $-3.87^{\circ} \mathrm{C}$. Almost all data were distributed under $3.6 \mathrm{~m} / \mathrm{s}$, which is the threshold wind speed of standing conditions of the Lawson criterion. There was no predominant characteristic of this figure. The meteorological data of respondents was distributed evenly between $T_{W C}=-10$ and $T_{W C}=0$. In general, male respondents tend to answer that the conditions are acceptable.

Figure $8 \mathrm{~d}$ shows the meteorological data of respondents who answered "clearly acceptable". The average values of respondents who answered they feel the conditions "clearly acceptable" were $-0.8{ }^{\circ} \mathrm{C}$ air temperature and $2.4 \mathrm{~m} / \mathrm{s}$ wind speed. This value is converted to WCET as $-2.22{ }^{\circ} \mathrm{C}$. Respondents answered that conditions acceptable when the wind speed is below $1.8 \mathrm{~m} / \mathrm{s}$, which is the threshold wind speed of long time sitting of Lawson criterion. Almost all respondents who answered the conditions were acceptable indicated that they feel comfort when the WCET is over $-2{ }^{\circ} \mathrm{C}$.

\section{Discussion}

Pedestrians feel discomfort when strong winds occur. Furthermore, pedestrians could feel discomfort when the WCET is low, even though the pedestrian wind comfort criteria are fulfilled. Many big cities located at mid-latitudes have hot summers and cold winters. In these cases, pedestrians could feel discomfort when the weather is cold. How can we adopt these results when evaluating pedestrian comfort?

Figure 9 shows the results of pedestrian perceptions towards outdoor environments and those who indicated that they feel discomfort. In general, pedestrians feel discomfort when the WCET is low. The blue zone refers to the region between $T_{W C}=-10$ and $T_{W C}=-3$. Overall, 91.6 percent of respondents belong to this region. The orange zone refers to the region between $T_{W C}=-10$ and $T_{W C}=-2$. Overall, 96.5 percent of respondents belong to this region. If the threshold wind speed of pedestrian comfort criteria is modified to $1.8 \mathrm{~m} / \mathrm{s}$ according to WCET in winter, over 90 percent of pedestrians could be covered by this region. Many pedestrians felt discomfort even though the wind speed was below the threshold wind speed. This graph suggests that the WCET could be more important in cold winters. Therefore, it is suggested that the threshold wind speed be changed to $1.8 \mathrm{~m} / \mathrm{s}$ when the outdoor air temperature is below $0{ }^{\circ} \mathrm{C}$. When evaluating outdoor wind comfort, the modified threshold wind speed needs to be lowered in winter, while the existing threshold wind speed should be applied in other seasons.

More studies are obviously needed to clarify this problem. To improve current pedestrian comfort criteria, we need to combine the concept of wind chill in winter with the existing pedestrian wind comfort criteria. By setting the standards of the WCET, the uncertainty of this suggestion could be clarified. The one thing we discovered from this study is that there are more pedestrians who feel discomfort even though the comfort criteria are fulfilled than many researchers perhaps expect. Therefore, the existing pedestrian comfort criteria could be improved by adopting this concept in winter conditions. 


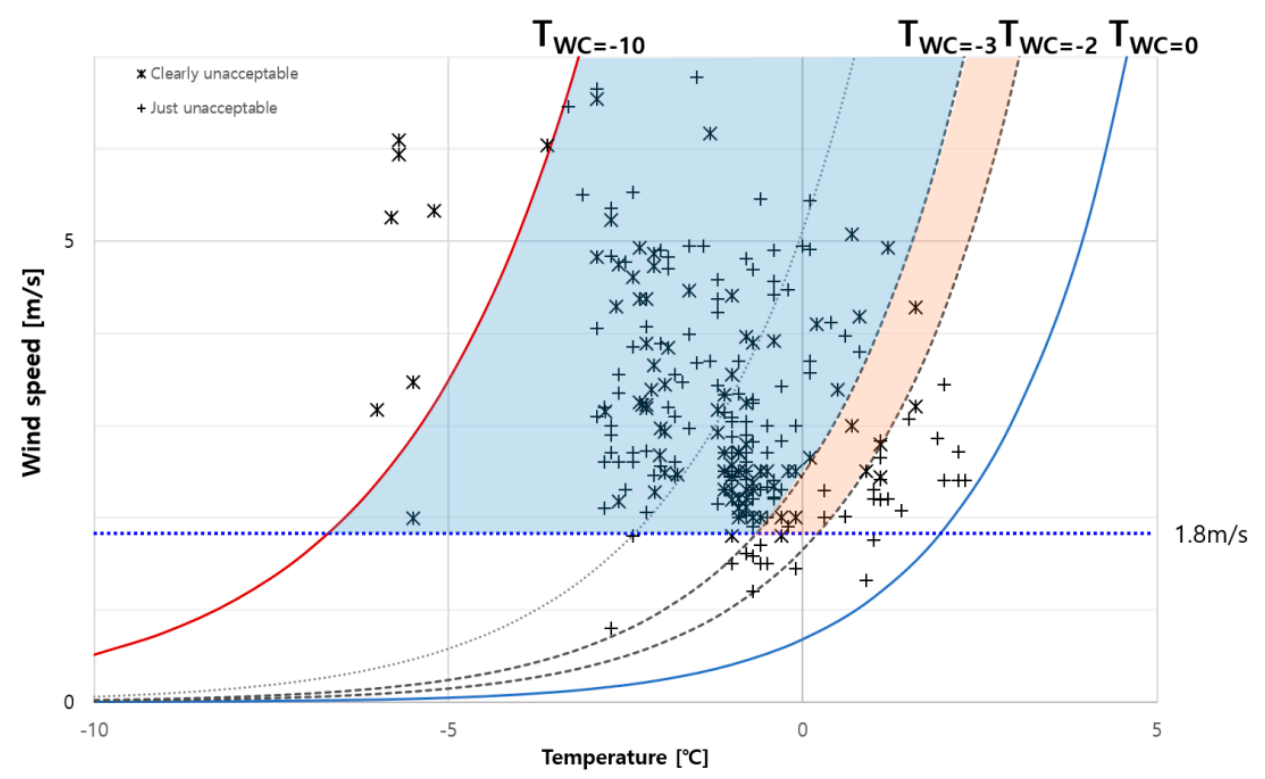

Figure 9. Comprehensive analysis of the result of pedestrian response and WCET.

\section{Conclusions}

In this study, pedestrian wind comfort was investigated using pedestrian surveys. In the process of investigating pedestrian comfort, the concept of pedestrian wind comfort and WCET were considered. By analyzing the meteorological data and the results of the survey of pedestrian perception, we could confirm that many pedestrians feel discomfort, especially in winter. The results of this study are summarized as follows.

(1) In winter, pedestrians feel discomfort even at low wind speeds. This is due to the convective heat loss caused by the wind, and this wind chill should be reflected in the design of outdoor wind environments. Since only the mechanical effects of the wind are considered by existing criteria, there are limits in assessing the comfort of pedestrians in winter.

(2) The threshold wind speed of the winter season could be determined to be lower than that of existing comfort criteria. WCET could be an alternative parameter that improves pedestrian wind comfort.

(3) Almost all pedestrians feel discomfort when the WCET is below -3. Overall, 91.6 percent of respondents who answered they feel discomfort belong to this zone. If the threshold wind speed is modified with respect to WCET in winter, the pedestrian comfort can be improved.

When outdoor wind environments are designed by applying the same threshold wind speed every year, pedestrians come to feel the discomfort caused by the wind chill in winter. It is expected that the adoption of the WCET proposed in this study makes it possible to improve the existing wind comfort criteria by adjusting the reference wind speed, thus helping to prevent discomfort caused by the wind in winter.

Acknowledgments: This research was supported by Basic Science Research Program through the National Research Foundation of Korea (NRF) funded by the Ministry of Science and ICT (NRF-2017R1A2B3012914).

Author Contributions: Hyungkeun Kim developed the proposed research, performed questionnaire survey and data analysis, and wrote the paper; Kyungsoo Lee performed questionnaire survey and field measurement, reviewed relevant literature; Taeyeon Kim helped to develop the main idea of this study and revised the manuscript.

Conflicts of Interest: The authors declare no conflicts of interest. 


\section{References}

1. Wise, A.F.E. Wind Effects Due to Groups of Buildings; Building Research Station Garston: Watford, UK, 1970.

2. Lawson, T.; Penwarden, A. The effects of wind on people in the vicinity of buildings. In Proceedings of the 4th International Conference on Wind Effects on Buildings and Structures, Heathrow, UK, 15 December 1975; pp. 605-622.

3. Penwarden, A.D. Acceptable wind speeds in towns. Build. Sci. 1973, 8, 259-267. [CrossRef]

4. Murakami, S.; Deguchi, K. New criteria for wind effects on pedestrians. J. Wind Eng. Ind. Aerodyn. 1981, 7, 289-309. [CrossRef]

5. Isyumov, N.; Davenport, A. The ground level wind environment in built-up areas. In Proceedings of the 4th International Conference on Wind Effects on Buildings and Structures, Heathrow, UK, 15 December 1975; pp. 403-422.

6. Netherlands Normalisation Institute (NEN). Nen 8100: Wind Comfort en Wind Danger in the Built Environment; Netherlands Normalisation Institute: Delft, The Netherlands, 2006.

7. Aerospace Division of ASCE. Outdoor Human Comfort and Its Assessment: State of the Art; American Society of Civil Engineers: Reston, VA, USA, 2004.

8. Arens, E.A. Designing for an acceptable wind environment. Transp. Eng. J. ASCE 1981, 107, 127-141.

9. Hoppe, P. Different aspects of assessing indoor and outdoor thermal comfort. Energy Build. 2002, 34, 661-665. [CrossRef]

10. Arens, E.; Bosselmann, P. Wind, sun and temperature-Predicting the thermal comfort of people in outdoor spaces. Build. Environ. 1989, 24, 315-320. [CrossRef]

11. Lai, D.Y.; Guo, D.H.; Hou, Y.F.; Lin, C.Y.; Chen, Q.Y. Studies of outdoor thermal comfort in northern china. Build. Environ. 2014, 77, 110-118. [CrossRef]

12. Soligo, M.J.; Irwin, P.A.; Williams, C.J.; Schuyler, G.D. A comprehensive assessment of pedestrian comfort including thermal effects. J. Wind Eng. Ind. Aerodyn. 1998, 77-78, 753-766. [CrossRef]

13. Szucs, A.; Moreau, S.; Allard, F. Spectators' aerothermal comfort assessment method in stadia. Build. Environ. 2007, 42, 2227-2240. [CrossRef]

14. Bottema, M. A method for optimisation of wind discomfort criteria. Build. Environ. 2000, 35, 1-18. [CrossRef]

15. Melbourne, W.H. Criteria for environmental wind conditions. J. Wind Eng. Ind. Aerodyn. 1978, 3, $241-249$. [CrossRef]

16. Lawson, T.V. The widn content of the built environment. J. Ind. Aerodyn. 1978, 3, 93-105. [CrossRef]

17. Metje, N.; Sterling, M.; Baker, C.J. Pedestrian comfort using clothing values and body temperatures. J. Wind Eng. Ind. Aerod. 2008, 96, 412-435. [CrossRef]

18. Toros, H.; Deniz, A.; Saylan, L.; Sen, O.; Baloglu, M. Spatial variability of chilling temperature in turkey and its effect on human comfort. Meteorol. Atmos. Phys. 2005, 88, 107-118. [CrossRef]

19. Blazejczyk, K.; Epstein, Y.; Jendritzky, G.; Staiger, H.; Tinz, B. Comparison of utci to selected thermal indices. Int. J. Biometeorol. 2012, 56, 515-535. [CrossRef] [PubMed]

20. Osczevski, R.; Bluestein, M. The new wind chill equivalent temperature chart. Bull. Am. Meteorol. Soc. 2005, 86, 1453-1458. [CrossRef]

21. National Weather Service (NWS). Available online: http://www.nws.noaa.gov/om/cold/wind_chill.shtml (accessed on 15 January 2018).

22. Tahbaz, M. Psychrometric chart as a basis for outdoor thermal analysis. Int. J. Arch. Eng. Urban Plan. 2011, 21, 95-105.

23. National Information Society Agency of Republic of Korea (NIA). Investigation of the Floating Population around the Subway Station and Major Commercial District; National Information Society Agency: Seoul, Korea, 2015.

(C) 2018 by the authors. Licensee MDPI, Basel, Switzerland. This article is an open access article distributed under the terms and conditions of the Creative Commons Attribution (CC BY) license (http://creativecommons.org/licenses/by/4.0/). 